\title{
A recepção do conceito de transitivismo de Charlotte Bühler na teoria lacaniana do estádio do espelho
}

\author{
Crístia Rosineiri Gonçalves Lopes Corrêa ${ }^{a *}$ (i) \\ Richard Theisen Simanke ${ }^{b}$ (i) \\ a Universidade Federal de Juiz de Fora, Instituto de Ciências Humanas, Programa de Pós-Graduação em Psicologia. Juiz de Fora, MG, Brasil \\ ${ }^{b}$ Universidade Federal de Juiz de Fora, Instituto de Ciências Humanas, Departamento de Psicologia. Juiz de Fora, MG, Brasil
}

\begin{abstract}
Resumo: 0 artigo examina a recepção por Lacan do conceito de transitivismo de Charlotte Bühler na elaboração de sua teoria do estágio do espelho entre os anos 1936-1949, a fim de mostrar como noções oriundas da psicologia do desenvolvimento da época foram incorporadas na construção de seu pensamento. Argumenta-se que a contribuição específica de Bühler foi decisiva tanto na formulação inicial do estágio do espelho quanto em seu desenvolvimento subsequente, culminando na versão de 1949, já mais próxima do antipsicologismo estruturalista. Em conclusão, discute-se como a rejeição de uma interpretação psicológica dos conceitos psicanalíticos não pode ser considerada característica originária da teoria lacaniana, surgindo apenas a partir de estágios posteriores de seu desenvolvimento.
\end{abstract}

Palavras-chave: Jacques Lacan, Charlotte Bühler, transitivismo, imaginário, estágio do espelho.

\section{Introdução}

Em 1932, na conclusão de sua tese de doutorado, Lacan (1932/1975) anuncia seu objetivo de continuar trabalhando com o conceito psicanalítico de narcisismo. Esse conceito e outros a ele relacionados, como o de ideal do eu ou supereu, estavam entre as contribuições psicanalíticas mais valorizadas por Lacan no contexto ainda psiquiátrico de sua tese (Simanke, 2002). A proposta de reformulação desses conceitos aparece, assim, como um projeto herdeiro de seu trabalho anterior como psiquiatra (Sales, 2005).

Conforme Lacan (1953) assinalaria depois, sua intenção era fornecer uma teoria genética do eu. Essa gênese transcorreria, fundamentalmente, na relação do sujeito com seu próprio corpo, pensada em termos de identificação com uma imago, que, para Lacan, seria a relação psíquica por excelência. Nesse contexto, ele define como "estádio do espelho" o período de desenvolvimento situado entre os seis e os dezoito meses, podendo se estender até dois anos ou dois anos e meio. Entre os seis e os oito meses, em geral, a criança passaria a reconhecer sua imagem no espelho. Essa é uma experiência que já havia sido descrita no âmbito da psicologia do desenvolvimento ou, mesmo, da psicologia comparada (Jalley, 2011).

Mas, no artigo de 1949, "O estádio do espelho como formador da função do eu" - a versão mais

\footnotetext{
* Endereço para correspondência: crlopes2001@yahoo.com.br
}

conhecida desse conceito lacaniano -, essas noções são retomadas com consideráveis modificações se comparadas com aquelas do período compreendido entre 1936 e 1938, quando o conceito de estádio do espelho recebe sua primeira formulação e, mesmo, nas elaborações posteriores, mais próximas ao texto de 1949. Entre essas diferenças, destaca-se a inclinação para uma abordagem estruturalista que se afasta do tom psicológico que caracterizou as formulações precedentes.

É bem conhecida a posição polêmica em relação à psicologia adotada por Lacan a partir do "Discurso de Roma" (1953/2005). No entanto, anteriormente, ele recorrera consistentemente à psicologia infantil de sua época, no intuito de fazer avançar sua revisão do conceito de narcisismo. Mas tais referências no campo da psicologia do desenvolvimento usadas por Lacan são pouco contextualizadas. Entre elas, destaca-se o trabalho de Charlotte Bühler (1893-1974). É verdade que nem todo o Lacan da primeira teoria do imaginário se explica pela psicologia do desenvolvimento do seu tempo. Embora a influência dessa psicologia sobre as concepções lacanianas seja relevante, ela é, ainda assim, "localizada e ponderável" (Jalley, 2011, p. 15). A mesma autora prossegue, reconhecendo que, "a partir dali, o percurso de Lacan seguiu seu próprio desenvolvimento, de uma originalidade irredutível a qualquer influência assinalável" (Jalley, 2011, p. 14). Lacan, contudo, por várias vezes reafirmará a importância teórica do estádio do espelho, após o período de formação de seu pensamento, quando já ficou para trás a referência a esses autores da psicologia do desenvolvimento. Sua releitura da teoria freudiana do narcisismo foi subsidiada por 
essas contribuições, que desempenharam assim um papel historicamente importante na formação do pensamento lacaniano. A compreensão desse processo de formação requer, então, a elucidação do contexto científico em que transcorreu e com o qual dialogou e que é bastante distinto daquele das etapas posteriores do seu pensamento.

Essa contextualização visa identificar e especificar o papel das contribuições encontradas por Lacan na psicologia do desenvolvimento, assim como estabelecer suas conexões teóricas. Embora seja o trabalho mais conhecido sobre o estádio do espelho, o artigo de 1949 não pode ser tomado como o único documento para o estudo da formação do pensamento lacaniano. Um dos problemas, justamente, é que nele a referência à psicologia do desenvolvimento já praticamente desapareceu ou permanece apenas subentendida.

Para iniciar o resgate desse aspecto do percurso inaugural de Lacan, este artigo se ocupa da sua recepção do conceito de transitivismo na sua teoria do estádio do espelho, encontrada por ele principalmente no trabalho de Charlotte Bühler. O transitivismo, em linhas gerais, é definido por Lacan como a forma cativante de uma captação pela imagem do outro. Desse modo, "ela [a criança] pode participar, num transe completo, do tombo de seu colega, ou igualmente lhe imputar, sem que se trate de mentira, ter recebido dele o golpe que lhe aplicou" (Lacan, 1950/1966, p. 180). Para Lacan, o transitivismo representa uma categoria de comportamento em que é possível observar a equivalência entre a ação da criança e a ação do outro. Ele evidencia um "momento de indeterminação da relação entre agente e paciente" (Dunker, 2011, p. 9). No comportamento transitivista, não é preciso duvidar da sinceridade da criança, pois, nele, o eu e o outro se confundem (Jalley, 2011).

Ao abordar o conceito de transitivismo, Lacan cita Charlotte Bühler diversas vezes. Trata-se, assim, de uma referência bastante explícita, mas que recebeu pouca atenção nos estudos lacanianos. Corniglio (2014) é uma das poucas exceções nesse sentido. $\mathrm{O}$ estudo das contribuições dessa autora permite, assim, estabelecer como as contribuições relativas ao conceito de transitivismo podem ser localizadas, contextualizadas e reconhecidas em seu alcance. Um conhecimento mais preciso quanto aos empréstimos tomados à psicologia do desenvolvimento de Bühler na recepção do conceito de transitivismo pode, desse modo, contribuir para explicitar a trama de referências a partir das quais o pensamento inicial de Lacan se constrói.

Para tanto, será realizada, em primeiro lugar, uma análise detalhada dos textos de Lacan pertinentes, visando caracterizar seu recurso ao conceito de transitivismo. A seguir, serão examinados os textos originais de Charlotte Bühler em que esse conceito se formula. Por fim, uma análise comparativa procurará estabelecer as aproximações e distanciamentos entre a teoria de Bühler e a teoria lacaniana da época, a fim de evidenciar o estilo do recurso lacaniano à psicologia do desenvolvimento que lhe foi contemporânea.

\section{O conceito de transitivismo nas formulações lacanianas do estádio do espelho entre 1936 e 1949}

Em agosto de 1936, em Marienbad, Lacan participa pela primeira vez de um congresso da International Psychoanalytical Association, apresentando um trabalho intitulado "O estádio do espelho". Decorridos dez minutos de exposição, a seção teria sido interrompida por Ernest Jones sob alegação de "falta de tempo". Com o ocorrido, Lacan teria abandonado o evento sem enviar o trabalho para publicação nos anais do Congresso. Essa teria sido a primeira versão da sua formulação do estádio do espelho. Cavalcante (2014) sublinha que a entrada de Lacan na psicanálise ficará, pois, marcada pela ausência do registro de um texto, na medida em que o que restou dessa versão foram somente as extensas notas tomadas pela psicanalista francesa Françoise Dolto (1908-1988) quando o trabalho fora anteriormente apresentado na Sociedade Psicanalítica de Paris. Jorge e Ferreira (2005) comentam que há, ainda, traços dessa versão inicial em dois trabalhos posteriores de Lacan: em duas questões formuladas ao final do artigo "Para-além do princípio de realidade" (Lacan, 1936/1966) e no verbete da Encyclopédie française intitulado "A família" (Lacan, 1938/1985).

O trabalho sobre a família faz parte do oitavo tomo da Encyclopédie française. Henri Wallon recebera a incumbência de dirigir o volume dedicado à psicologia, delegada por seu amigo, o historiador francês Lucien Febvre (1878-1956), diretor-geral do projeto. Ele mobiliza, então, um grupo bem diversificado para realizá-lo. No total, foram 28 colaboradores dos campos da psicologia, sociologia, história, etologia, d neurologia, psiquiatria e psicanálise. No que diz respeito à psicanálise, a Édouard Pichon (1890-1940) coube o verbete "A psicanálise", a Daniel Lagache (1903-1972), "A sexualidade", enquanto a Lacan fora confiado o verbete sobre "A família".

Embora o texto original da intervenção de 1936 pareça ter sido definitivamente perdido, ele parece ter sido integrado na dimensão maior do artigo sobre $O s$ complexos familiares ${ }^{1}$. Ao procurar descrever ali a agressividade como signo da constituição de um "eu" que se passa em uma relação originariamente conflitiva com o "outro" do qual ele se destaca, Lacan irá "recorrer, pela primeira vez num escrito publicado, à sua teoria do estádio do espelho" (Simanke, 2002, p. 265).

Em Os complexos familiares, o complexo de intrusão ou complexo fraterno é situado entre os seis meses e os dois anos de idade. Com isso, ele coincide cronologicamente com a fase do estádio do espelho. Desse modo, o estádio do espelho é associado ao declínio do complexo de desmame ou, mais exatamente, ao complexo de intrusão que o sucede, tendo como pano de fundo uma característica biológica específica do sujeito humano, que

1 Os complexos familiares é o título sob o qual o trabalho foi republicado sob a forma de livro nos anos 1980. 
é a prematuração ao nascer. O atraso no desenvolvimento do sistema nervoso central durante os seis primeiros meses provoca no bebê um estado de impotência vital e de miséria psicológica, ligado à descoordenação motora. Esta, por sua vez, resulta em sensações proprioceptivas que fornecem a base para uma apreensão subjetiva do corpo como algo incongruente, que se expressa na fantasia do corpo despedaçado (corps morcelé).

Nesse contexto, Lacan aborda o complexo de intrusão como constitutivo da experiência da criança ao deparar com a presença de seus semelhantes. A reação de rivalidade que caracteriza essa experiência seria imanente à sociabilidade enquanto tal, que se desenvolve a partir daí. É nesse contexto que ele aborda os fenômenos em que duas crianças entre seis meses e dois anos, aproximadamente, se confundem e reagem com agressividade uma com relação à outra quando ficam juntas, configurando uma reação de "rivalidade objetivamente definível”, que, segundo Lacan (138/1985), não deixa de ser uma "das reações diversas nas quais parece manifestar-se uma comunicação" (p. 31).

Em outras palavras, crianças nessa faixa etária apresentam reações comunicacionais e imitativas entre si. Esse tipo de reação precoce inclui certa adaptação das posturas e dos gestos entre as crianças, configurando "uma conformidade em sua alternância, uma convergência em sua série, que os ordenam em provocações e respostas, permitindo afirmar, ... que eles realizam a situação como tendo dupla saída, como uma alternativa" (Lacan, 1938/1985, p. 31). Essa adaptação, segundo Lacan, representaria o esboço do reconhecimento de um rival, ou seja, do "outro" como objeto. Ele assinala que essa reação precoce é determinada por certo limite de diferença de idade entre as crianças que não pode ser ultrapassado. Esse limite seria de cerca de dois meses e meio no primeiro ano do período considerado.

Lacan passa, então, a examinar as reações de exibição, sedução e despotismo entre as crianças. Argumenta que a relação que caracteriza essas reações se apresenta como um conflito entre duas atitudes opostas e complementares de cada criança, sendo essa participação bipolar constitutiva da própria situação. Trata-se, para Lacan, nessa experiência, da realização do paradoxo concernente à confusão, em cada parceiro, de seu próprio papel com o papel do outro. Em suma, cada criança se confunde com o outro, identificando-se com ele.

O problema que Lacan quer equacionar, nesse ponto, é a constituição imaginária simultânea do eu e do objeto. Assim, a elaboração do estádio do espelho disponibilizará uma base para pensar a constituição do eu como reflexo da relação de rivalidade, cujas características possibilitaram conceber a constituição imaginária do outro como objeto. A relação imaginária "constitutiva com o outro é, primariamente, uma relação de disputa" (Simanke, 2002, p. 266). Daí decorre que a agressividade se encontre intimamente vinculada ao narcisismo, tal como Lacan explicitará categoricamente no artigo "A agressividade em psicanálise” (Lacan, 1948/1966).
Para Lacan, o narcisismo representa, antes de tudo, a antecipação imaginária de uma representação corporal coordenada e funcional, em contraste com a vivência proprioceptiva de um organismo que padece da prematuridade biológica. A experiência dessa prematuridade se expressa na fantasia do corpo despedaçado. Por conseguinte, o narcisismo provê um tipo de sutura para a superação do trauma do desmame, que terminou por mergulhar o sujeito no seu desamparo primordial. Desse modo, a presença do irmão ilustra a constituição do eu narcísico e, também, a culminação do narcisismo. Esse é o sentido da assertiva lacaniana em Os complexos familiares: "o eu se constitui ao mesmo tempo que o outro no drama do ciúme" (Lacan, 1938/1985, p. 34). No drama do ciúme expresso na disputa por um objeto, este passa a ser investido pelo desejo apenas por ser desejado pelo outro.

Em Os complexos familiares, texto publicado que mais traz as formulações de Lacan de 1936, o estádio do espelho se apresenta como uma experiência própria do "complexo de intrusão", em que o rival é representado, de modo exemplar, pela figura do irmão. Nesse trabalho ocorre uma única vez o termo "transitivismo". Para Lacan, nesse momento, o transitivismo é uma categoria de comportamento em que é possível observar a equivalência, para a criança, entre sua própria ação e a ação do outro, havendo, pois, nesse comportamento um espelhamento instável entre a criança e seu semelhante (Jalley, 2011). Eis, então, como Lacan se refere ao transitivismo em Os complexos familiares:

Digamos que o eu conservará dessa origem a estrutura ambígua do espetáculo que, manifesto nas situações . . . descritas do despotismo, da sedução, da exibição, dá sua forma a pulsões, sadomasoquista e escoptofílica (desejo de ver e ser visto), em sua essência destruidoras do outro. Notemos, também, que essa intrusão primordial faz compreender toda projeção do eu constituído, quer ela se manifeste como mitomaníaca na criança cuja identificação pessoal ainda vacila, como transitivista no paranoico, cujo eu regride a um estádio arcaico, ou como compreensiva quando é integrada num eu normal. (Lacan, 1938/1985, pp. 38-9, grifos nossos)

Embora o termo "transitivismo" apareça uma única vez, Lacan aborda os fenômenos do despotismo, da sedução e da exibição, que ocorrem quando duas crianças pequenas, entre seis meses e dois anos, ficam juntas, se confundem e reagem com agressividade uma à outra, configurando uma reação de "rivalidade objetivamente definível" (Lacan, 1938/1985, p. 31).

Essas situações lhe permitirão analisar o impacto da presença do irmão, reivindicando, a partir disso, que "o eu se constitui ao mesmo tempo que o outro no drama do ciúme" (Lacan, 1938/1985, p. 34), sendo que esse "outro" rival se cristaliza na figura do irmão e encontra aí sua primeira expressão. Há, pois, uma subordinação ou 
mesmo uma assimilação do drama do ciúme primordial ao comportamento "transitivista". O próprio Lacan indica, na passagem citada, ao assinalar que essa intrusão primordial faz compreender como "transitivista" toda projeção do eu constituído, cuja identidade pessoal ainda vacila. Portanto, mesmo que Bühler não seja ainda mencionada explicitamente com relação ao tema do "transitivismo" e que a formulação que concerne à cristalização do "outro" rival na figura do irmão seja própria de Lacan, é possível antecipar que as situações descritas (exibição, sedução, despotismo), assim como a subordinação do ciúme aos fenômenos do "transitivismo", permitem vislumbrar o impacto das contribuições da autora alemã já no texto de 1938.

Em 1946, numa intervenção nas jornadas psiquiátricas de Bonneval, Lacan retoma os aspectos principais de sua teoria do estádio do espelho. Depois, essa intervenção originou o trabalho Formulações sobre a causalidade psíquica, publicado apenas em 1950. Nele, o conceito de "transitivismo" reaparece como uma reação peculiar à experiência da assunção pela criança da imagem especular: "a forma cativante de uma verdadeira captação pela imagem do outro" (Lacan, 1950/1966, p. 180). Nesse escrito, Charlotte Bühler já é mencionada explicitamente:

Deixo de lado a série dos fenômenos que vão da identificação especular à sugestão mimética e à sedução da imponência. Todos eles são incluídos por essa autora [Bühler] na dialética que vai do ciúme (esse ciúme cujo valor iniciático Sto. Agostinho já entrevia de modo fulgurante) às primeiras formas da simpatia. Eles se inscrevem numa ambivalência primordial que nos aparece, já o indico, em espelhamento, no sentido de que o sujeito se identifica, em seu sentimento de si, com a imagem do outro, e de que a imagem do outro vem cativar nele esse sentimento. Ora, essa reação só se produz sob uma condição: a de que a diferença de idade entre os parceiros fique abaixo de certo limite que, no início da fase estudada, não poderia ultrapassar um ano. Já se manifesta aí um traço essencial da imago: os efeitos observáveis de uma forma, no sentido mais amplo, que só pode ser definida em termos de semelhança genérica e que, portanto, implica como primitivo certo reconhecimento. (Lacan, 1950/1966, pp. 180-181)

Lacan destaca como a criança, durante a fase especular, se refere a si mesma na terceira pessoa, localizando aí o "transitivismo", e novamente se refere às contribuições da psicologia do desenvolvimento de Bühler:

Charlotte Bühler, de fato, para citar apenas ela, observando o comportamento da criança com seu companheiro de brincadeiras, reconheceu esse transitivismo sob a forma cativante de uma verdadeira captação pela imagem do outro. Assim, ela pode participar, num transe completo, do tombo de seu colega, ou igualmente lhe imputar, sem que se trate de mentira, ter recebido dele o golpe que lhe aplicou. (Lacan, 1950/1966, p. 180)

Esse conceito de "transitivismo" será retomado pelo autor em "A agressividade em psicanálise", de 1948, e em "O estádio do espelho como formador da função do eu", de 1949. No primeiro, Lacan destaca que a primeira captação pela imagem, em que se delineia o momento inaugural da dialética das identificações, está ligada a um fenômeno de Gestalt, à percepção muito precoce da forma humana, na criança, que "fixa seu interesse desde os primeiros meses e, mesmo, para o rosto humano, desde o décimo dia de vida" (Lacan, 1948/1966, p. 112). No entanto, para o autor, a jubilação triunfante e o interesse lúdico pelo discernimento de si na imagem especular são os sinais que evidenciam o fenômeno de reconhecimento implicado na construção de subjetividade. Desse modo, a partir da influência do trabalho de Baldwin (Lyden, 2008), ele antecipa algo que será proposto no artigo de 1949, quando destaca o fato de que a criança seja capaz de reconhecer como sua uma imagem no espelho, interessando-se por essa imagem, justamente numa fase em que ainda é superada pelo chimpanzé em sua inteligência instrumental, ao passo que o animal desvia sua atenção do espelho rapidamente, tão logo se dê conta de que a imagem não passa de um reflexo.

No próprio enunciado da Tese IV desse mesmo trabalho, Lacan postula uma relação estreita entre identificação narcísica e agressividade: "A agressividade é a tendência correlativa de um modo de identificação que chamamos narcísico e que determina a estrutura formal do eu do homem e do registro de entidades característico de seu mundo" (Lacan, 1948/1966, p. 110). A agressividade que se manifesta na rivalidade adviria da experiência da discrepância entre a síntese representada pela imagem especular e as sensações corporais vivida pela criança que lhe anunciam sua fragmentação. "Assim, essa discrepância é vivida primeiramente como rivalidade porque a unidade do reflexo sublinha a falta de unidade real"'(Sales, 2005, p. 122).

Lacan diz que a forma do estádio do espelho se cristalizará na tensão conflitiva interna experimentada pelo sujeito, determinando o despertar de seu desejo pelo objeto do desejo do outro. A relação com o outro imaginário será, pois, intrinsecamente ambivalente: erótica e agressiva, sendo a agressividade direcionada tanto ao objeto quanto a si mesmo: "Enfim, para Lacan, a relação narcísica já é a relação com o outro, já é amá-lo e odiá-lo simultaneamente, porque implica tanto identificação quanto agressividade" (Sales, 2005, p. 123). Por conseguinte, nesse momento, a gênese da agressividade se situa precisamente nessa constituição imaginária simultânea do eu narcísico e do outro como objeto.

Nesse contexto, Lacan destaca a captação pela imago da forma humana, que domina toda a dialética do comportamento da criança na presença de seu semelhante, fazendo notar as reações emocionais e os testemunhos articulados de um transitivismo normal no âmbito dessa 
experiência especular. Tanto em "Formulações sobre a causalidade psíquica" quanto no trabalho "A agressividade em psicanálise", e também em "O estádio do espelho como formador da função do eu" (Lacan, 1950/1966, 1948/1966; 1949/1966), o transitivismo é uma categoria de comportamento em que é possível observar a equivalência, para a criança, entre sua ação e a ação do outro. Ela diz, por exemplo, "François bateu em mim", ao passo que foi ela quem bateu em François. Há, nesse comportamento transitivista, como que um espelho instável entre a criança e seu semelhante. Desse modo, Lacan propõe uma matriz para a estruturação do eu que tem o transitivismo como lei, ilustrando exemplarmente o princípio de que "o eu é um outro". Em outras palavras, nas relações especulares caracterizadas pelo comportamento transitivista, os limites entre o corpo de um e o corpo do outro se desfazem. Para Jalley (2011), Lacan evoca o narcisismo como conceito conexo ao conceito de transitivismo, utilizando essa noção "como o descritor principal da organização psíquica própria do estádio do espelho" (p. 54).

Em 17 de julho de 1949, mais de dez anos depois da publicação do trabalho sobre os complexos familiares, Lacan faz uma nova comunicação no congresso da International Psycho-Analytical Association, dessa vez em Zurich. Esse trabalho, intitulado "O estádio do espelho como formador da função do eu tal qual ela nos é revelada na experiência psicanalítica", foi depois publicada nos Escritos.

Lacan retoma o fato, já destacado nos trabalhos anteriores, de que, quando a criança se torna capaz de reconhecer uma imagem no espelho como sua, passa a se interessar vivamente por essa imagem, ao contrário do que os dados da psicologia comparada revelam sobre o comportamento de outras espécies de primatas também capazes desse reconhecimento. A criança reconhece sua imagem no espelho com uma manifestação de euforia e júbilo, que evidenciam uma operação de identificação, no sentido da "transformação produzida no sujeito quando ele assume uma imagem" (Lacan, 1949/1966, p. 94). O processo de identificação envolve uma função de antecipação, que é exercida pela Gestalt perceptiva, produzindo a miragem de uma maturação ainda não realizada da potência e da autonomia do sujeito. Para Lacan, essa Gestalt constitutiva é mais constituinte do que constituída. Esse poder formador da imagem é, segundo ele, confirmada por evidências biológicas, por exemplo, a maturação das gônadas na pomba, que tem como condição necessária a visão de um congênere, não importando o sexo, sendo que, na ausência de outro indivíduo da mesma espécie, até mesmo seu reflexo no espelho pode desencadear o processo. Sobre isso, Verstegen (2015) argumenta pela presença de um mecanismo para suturar a realidade em contraste com a ênfase sobre a subjetividade dividida da teoria lacaniana posterior.

Lacan enfatiza como esse poder formador da imagem se manifesta ainda mais intensamente no homem, em função das circunstâncias trazidas por sua prematuridade biológica. A imagem desempenha justamente a função de suprir as deficiências ocasionadas pela neotenia e pela fetalização do animal humano imaturidade do adulto e prematuridade do recém-nascido (Bolk, 1926/1961) - e de preencher a lacuna deixada pela falta de relações fisiológicas suficientes com o meio, passando, então, a mediar a relação do homem com o mundo: "A função do estádio do espelho consiste, para nós, desde então, num caso particular da função da imago, que é a de estabelecer uma relação entre o organismo e sua realidade" (Lacan, 1949/1966, p. 96). Baseando-se nas deficiências causadas pela neotenia e pela fetalização, Lacan enfatiza a discordância entre a imagem visualmente harmônica refletida no espelho e a experiência subjetiva da criança, marcada por sensações de despedaçamento e de falta de coordenação. Ele retoma teses que já haviam sido apresentadas no artigo sobre os complexos familiares, afirmando que a saída do estádio do espelho precipita o sujeito na dialética da identificação com o outro, levando à formação das relações sociais e à constituição da realidade e do conhecimento (Sales, 2005). Ao fazer isso, ele confere um destaque mais explícito ao conceito de transitivismo, recolhido nas contribuições de Charlotte Bühler à psicologia do desenvolvimento infantil.

Esse momento em que se conclui o estádio do espelho inaugura, pela identificação com a imago do semelhante e pelo drama do ciúme primordial (tão bem enfatizado pela escola de Charlotte Bühler nos fenômenos de transitivismo infantil), a dialética que desde então liga o $e u$ a situações socialmente elaboradas. (Lacan, 1949/1966, p. 98)

Uma vez realizado esse percurso pelos principais trabalhos do período de elaboração da teoria lacaniana do imaginário (1936-1949), é preciso abordar mais diretamente as contribuições relativas ao conceito de transitivismo na psicologia do desenvolvimento de Charlotte Bühler. O objetivo é melhor situar e avaliar o impacto das contribuições da psicóloga alemã para as formulações lacanianas.

\section{O conceito de transitivismo de Charlotte Bühler}

$\mathrm{O}$ conceito de transitivismo tem origem no campo da psiquiatria alemã do final do século XIX, com o neurologista e psiquiatra alemão Carl Wernicke (1848-1905). Wernicke buscava compreender determinadas atitudes de seus pacientes, como quando estes lhe relatavam terem ido à consulta acompanhando alguém, ao passo que essa pessoa é que, na realidade, os acompanhava.

Essa categoria de comportamento foi também abordada por Henri Wallon em As origens do caráter na criança, baseando-se em Wernicke, mas transpondo esse conceito do campo da psiquiatria para o da psicologia. Para Wallon, esse fenômeno seria característico do desenvolvimento infantil e se referiria ao instante em que "a criança distribui, sem erro, entre ela e o outro, 
os estados ou atos percebidos" (Wallon, 1989, p. 242). Quanto a isso, menciona um exemplo tomado de Elsa Köhler (1879-1940), discípula de Charlotte Bühler, no qual duas crianças pequenas, sentadas próximas à governanta, brincavam com espuma, quando então uma delas começou a ficar inquieta e, bruscamente, bateu na outra e a empurrou. Questionada pela governanta sobre o que estava fazendo, respondeu que a coleguinha era implicante e havia batido nela.

Embora haja indícios de que Wallon tenha sido também uma referência para a apropriação do conceito de transitivismo na abordagem lacaniana do estádio do espelho, essa referência não aparece explicitamente (Jalley, 2011). Antes, conforme observado anteriormente, já no artigo lacaniano "Formulações sobre a causalidade psíquica” (Lacan, 1950/1966), o crédito da formulação do conceito é dado a Charlotte Bühler. A análise dos escritos do período de elaboração da sua teoria do imaginário (1936-1949) mostra a importância que as contribuições da psicóloga alemã adquirem aos olhos de Lacan. Dito de outro modo, a insistência de Lacan em apresentar Charlotte Bühler como fonte importante para suas elaborações indica seu papel fundamental na recepção lacaniana do conceito de transitivismo (Oliveira, 2017). No entanto, quase nada se encontra na literatura sobre as contribuições de Charlotte Bühler a um tema tão importante para a teoria psicanalítica lacaniana. Justifica-se, portanto, uma análise atenta das contribuições de Bühler para a formulação da teoria do imaginário. Pode-se argumentar, por exemplo, que as contribuições de Bühler são explicitamente reconhecidas por Lacan, ainda que seu trabalho seja muito raramente abordado em sua relação com o autor psicanalítico. Por isso é preciso atentar para as formulações relacionadas ao transitivismo, especificamente apresentadas por Charlotte Bühler com o objetivo de avaliar seu impacto sobre as elaborações lacanianas acerca desse conceito nas suas formulações do estádio do espelho. De acordo com Corniglio (2013), os estudos psicológicos e sociológicos sobre o primeiro ano de vida serão citados por Lacan no momento de fornecer as referências bibliográficas sobre os fenômenos transitivistas. Lacan dará a essa noção um uso amplo, que abarcará múltiplos fenômenos clínicos, tais como captação agressiva pela imagem do rival, a série das atitudes despóticas entre crianças e a atribuição dos próprios atos a terceiros. Nessa série, Lacan identificará a confusão imaginária entre uma e outra criança, destacando o drama do ciúme primordial no cerne da conduta transitivista. Desse modo, é possível verificar que os fenômenos transitivistas trabalhados por Lacan se beneficiam mesmo das contribuições de Bühler.

Charlotte Bühler, a partir dos anos 1920, realiza uma ampla investigação sobre a psicologia do desenvolvimento infantil, tendo como objetivo principal examinar o comportamento social das crianças desde a mais tenra infância (Corniglio, 2014). Com isso, Bühler se tornou uma das principais referências na psicologia do desenvolvimento infantil da época, influenciando teorias psicológicas do desenvolvimento, como a teoria walloniana e a psicologia histórico-cultural de Vygotsky, entre outras. Quanto a este, um dos impactos mais notáveis está em suas formulações sobre o caráter social da linguagem na criança, que se manifesta muito precocemente, ponto em que diverge explicitamente da abordagem piagetiana.

Entre as observações sistemáticas do comportamento social da criança desde o primeiro ano de vida, Bühler (1931/1959) acompanha 114 crianças da faixa etária entre três meses e um ano, em atendimento numa clínica de enfermagem. As observações ocorriam durante cerca de dez minutos em dias alternados. A maior parte das crianças se concentrava na faixa etária de cinco meses. Nessas observações, as crianças eram colocadas em situações que variavam na quantidade de indivíduos presentes (pares, trios ou mais) como também em idade (a mesma ou diferente). Eram usados brinquedos para estimulá-las, distribuindo-se um para cada criança, somente um para todas ou, ainda, sem utilizar qualquer brinquedo. Bühler observou que, mesmo bebês com três e quatro meses, a despeito de permanecerem no colo materno, voltavam o olhar para os outros bebês. Nesse contexto, Bühler destaca o sorriso como a primeira atitude social dos bebês intencionalmente direcionada aos adultos. Além do sorriso, ela menciona o contato com o olhar, os barulhos, os gestos (como tentativas de tocar ou agarrar), os sons inarticulados, os balbucios e as primeiras palavras como tipos de reações que indicam tentativas de comunicação, isto é, interações sociais precoces que se fazem presentes já a partir dos cinco meses.

Essas reações lhe permitem concluir que a criança se torna socialmente ativa a partir dessa idade, buscando espontaneamente contato e comunicação por meio dos balbucios e das aproximações físicas, como segurar e tocar (Bühler, 1927/1934). Além disso, nessa idade ou mesmo antes, podem ser observados gestos em direção a outras crianças, ao passo que, já no oitavo mês de vida, é possível perceber uma surpreendente capacidade para interpretar e compreender o outro. A autora chama, então, de "transitividade" essa trama identificatória especular com o semelhante nessa fase da vida infantil, indicando que a criança se identifica e se confunde com a imagem do corpo do outro. Como exemplo, menciona uma criança que chora ao ver outra chorar ou, mesmo, ao ver outro pequeno semelhante cair, como se o tombo tivesse ocorrido com ela. Cita observações de crianças dessa idade buscando consolar uma criança assustada e chorando junto, como também crianças fazendo esforços para excluir e evitar um companheiro, podendo, a partir dos dez meses, esse comportamento ser acompanhado por um sorriso de triunfo.

Nesse contexto, Bühler (1927/1934) afirma que a criança possui competências sociais precoces, argumentando que essa capacidade de interação social teria sido negligenciada pela psicologia do desenvolvimento até 
aquele momento. Segundo ela, já podem ser observados nas crianças pequenos "gestos de aproximação e de troca", com a criança mais velha se agitando e se mostrando, ao passo que a menor a observa, cativada pela experiência. Esse modo de relação dá forma a situações de exibição, que são determinadas por condições bem definidas; por exemplo, a diferença de idade entre as duas crianças não deve ultrapassar cerca de dois meses e meio. À medida que a idade aumenta, a relação entre as crianças fica mais equilibrada, esboçando-se a possibilidade de uma mudança de papéis.

Bühler (1931/1959) nota que uma criança com apenas seis meses já é capaz de interagir com outros bebês, procurando contato com estes por meio de atividades lúdicas, mesmo através de brincadeiras completamente separadas, que transcorram lado a lado. Pois, ainda que cada criança brinque paralelamente às outras, elas eventualmente trocam olhares, sorriem e mostram alguma coisa uma para a outra, inclusive com os bebês participando do contexto geral. De acordo com Oliveira (2017), "a autora afirma que a companhia lúdica começa com uma troca, oferecimento e apresentação mútua de coisas para jogar e brincar, e isso pode configurar um verdadeiro jogo entre os dois" (p. 61).

Ademais, para Bühler (1927/1934), a partir de seis meses, as crianças interagem trocando olhares, carícias, brinquedos e inclusive agressões ciumentas. Pois, antes dessa idade, "mesmo que um brinquedo seja tirado das crianças mais novas, elas estão tão ocupadas em olhar que ter ou pegar a coisa não significa nenhuma perda e de nenhuma maneira elas parecem prejudicadas" (p. 55). Já a partir da idade de seis meses, na modalidade de interação da agressão ciumenta, a criança rivaliza com o outro caso se interesse por um brinquedo que se torne objeto de disputa, mesmo que esteja apenas tomada pelo desejo de obter o brinquedo que despertou seu interesse, não prestando atenção ao companheiro de jogo. $\mathrm{O}$ bebê quer o brinquedo de interesse para si e, para isso, toma-o das mãos do outro.

Essa intrusão na esfera vital de outra criança, vista de fora, pela atividade de capturar com as mãos, começa aos seis meses. Mas, como é o brinquedo na mão do outro para onde a criança chega para pegar, a apreensão se converte de repente numa usurpação, num movimento das mãos no ato social. (Bühler, 1931/1959, p. 53)

Bühler considera a existência de crianças que nunca se envolvem por iniciativa própria com outras crianças, permanecendo na defensiva, configurando um comportamento de indiferença (Oliveira, 2017), mas suas observações apontam o último terço do primeiro ano de vida como a fase em que a criança manifesta tipicamente satisfação e prazer no triunfo sobre um rival. Nessa modalidade, incluem-se crianças agressivas, interessadas em qualquer objeto que outra criança possa ter em mãos, tentando agarrá-lo imediatamente. Esses sentimentos de satisfação e prazer em triunfar sobre o colega rival se produzem a partir do domínio obtido numa situação específica de disputa e ciúme vivida pela criança. "O sorriso e a mímica estão já muito diferenciados somente no segundo semestre, em particular é impressionante o sorriso de triunfo, que não se esperaria ver tão precocemente" (Bühler, 1927/1934, p. 102).

Bühler (1927/1934) nota, pois, que, quando o pequeno semelhante entra no campo subjetivo da criança, podem surgir os comportamentos de despotismo ou subordinação, com as crianças mais velhas subjugando as mais novas. Enquanto, nos comportamentos de rivalidade, podem-se encontrar golpes mútuos entre as crianças ou disputa por um objeto, nos comportamentos de despotismo estes são integrados às atitudes de subordinação, em que um depende do outro, ainda que em papéis opostos. Esses comportamentos de despotismo e subordinação podem variar, podendo assumir formas tais como a de dominar brutalmente o outro devido a um objeto de interesse, o despotismo de zombaria, ao oferecer e tirar um objeto do parceiro submisso ou, ainda, o despotismo de sedução. Para Bühler, assim como nas situações de exibição, esses comportamentos se encontram limitados pela diferença de idade entre as crianças. Enquanto a diferença de idade não pode superar dois meses e meio nos casos das relações de rivalidade, nas relações de despotismo pode haver uma diferença de idade maior, ultrapassando os três meses. No caso do despotismo, a iniciativa é tomada pelo mais velho, com exceção da relação entre menino e menina, em que, mesmo mais nova, a menina pode tomar a dianteira diante do menino:

Uma criança dos 6 a 11 meses empurra o outro ou arranca da mão o brinquedo, então sorri triunfante; o outro fica, ainda, inibido e não se atreve a defender-se. Os rebeldes saltam sobre o adversário e arrebatam de volta o mesmo brinquedo. Isso significa que, no segundo semestre, verifica-se acentuada as relações de rivalidade, despotismo e submissão hierárquicas. Esta situação é aplicada, muito em breve, na consciência das crianças de oito a dez meses. Em qualquer situação lúdica entre crianças de oito meses, prolongada por mais de alguns minutos, os dois acabam igualmente como parceiros, superior e inferior, respectivamente. (Bühler, 1931/1959, p. 52)

Para Bühler, após um período de pico de luta por brinquedos e jogos que vai dos 9 aos 13 meses de idade, as crianças, no período que vai dos 14 aos 25 meses, chegam a atitudes de relativa cooperação, por exemplo, trocar brinquedos e brincar com um mesmo brinquedo. Ela considera, contudo, que a formação de grupos somente surge por volta do $15^{\circ}$ mês, com atividades simples tais como a interação em torno de um mesmo objeto: "Ela cita como ilustração um tambor ao redor do qual mais 
de uma criança pratica a brincadeira de tocar. E só a partir de três anos essa interação é ampliada" (Oliveira, 2017, p. 60). Portanto é apenas a partir dos três anos de idade que é possível notar uma interação efetiva entre as crianças. Essas interações podem continuar resultando em atitudes de agressão ou de ciúme, mas agora são dotadas de um nítido sentido de desenvolvimento dos comportamentos sociais.

Desse modo, pode-se constatar como Charlotte Bühler descreveu substancialmente o drama do ciúme primordial presente nos fenômenos do transitivismo, indicando, principalmente nas situações de exibição, de despotismo e de sedução, a inclusão do ciúme no conjunto dos comportamentos transitivistas. Essas contribuições da psicologia do desenvolvimento da autora foram mencionadas diversas vezes nos escritos lacanianos a partir dos anos 1940, mas já podem ser encontradas de modo significativo no trabalho sobre os complexos familiares. Cabe avaliar, então, a título de conclusão, a função dessas referências e o estilo geral da recepção das ideias de Bühler por Lacan.

\section{Considerações finais}

Em relação ao seu conceito de transitivismo, nos trabalhos produzidos entre 1936 e 1949, já no artigo "Formulações sobre a causalidade psíquica" (Lacan, 1950/1966), os créditos por esse conceito são concedidos enfaticamente a Charlotte Bühler, evidenciando um nítido interesse de Lacan pelas ideias específicas dessa autora. Como se viu, Bühler chama de transitividade a trama identificatória especular, própria de uma fase da vida da criança em que ela se identifica e se confunde com a imagem do corpo do outro. Como exemplo, menciona uma criança que chora ao ver outra chorar ou, ainda, ao vê-la cair, como se o tombo tivesse ocorrido a ela mesma, narrando diversas histórias ilustrando esse tipo de experiência, o que parece ter chamado atenção de Lacan, como se viu nas passagens comentadas acima.

A referência de Lacan ao transitivismo, relacionando-o, por exemplo, à "forma cativante de uma verdadeira captação pela imagem do outro", mas também acrescentando o fato de a criança "lhe imputar também, sem que se trate de mentira, ter recebido o golpe que lhe aplicou" (Lacan, 1950/1966, p. 180), já indica um nível mais complexo de relação que a simples série despotismo, sedução, exibição, pois envolve a linguagem. Para Jalley (2011), apesar do elemento simbólico, esse tipo de comportamento foi apresentado por Lacan no contexto de seu exame da imagem especular, abordando-o, pois, como algo próprio da relação imaginária. De fato, somente a partir de reformulações posteriores o transitivismo deixa de ser abordado na teoria lacaniana apenas como um fenômeno dual, passando a levar em conta a referência a um terceiro, como a posição da governanta, na observação de Elsa Köhler mencionada por Wallon. Com isso, o transitivismo passa a ser considerado também como um fenômeno "triádico, pois é para um Outro que a criança apela em busca de um testemunho" (Dunker, 2011, p. 8).

No trabalho sobre os complexos familiares (Lacan, 1938/1985), o estádio do espelho é apresentado apenas como algo pertencente à trama do complexo de intrusão, sendo analisado em função da presença do irmão rival (Simanke, 2002). O interesse teórico de Lacan está centrado, sobretudo, no tema do ciúme fraterno, que desempenha um papel fundamental nesse texto (Jalley, 2011). No entanto, a partir dos escritos dos anos 1940, o irmão rival no complexo de intrusão passa "a ser substituído pela forma mais geral da presença do outro" (Sales, 2005, p. 114). Com isso, o transitivismo se torna um tema relativamente independente do contexto específico do complexo da intrusão. A partir de "O estádio do espelho como formador da função do eu" (Lacan, 1949/1966), o próprio tema do ciúme cede em importância, subordinando-se à noção do transitivismo, que passa então a ser a categoria organizadora central desse aspecto do pensamento de Lacan (Jalley, 2011, p. 66).

Como se viu, as situações de exibição, sedução e despotismo - nas quais, entre outras coisas, se explicita essa subordinação do ciúme ao comportamento transitivista - foram experiências significativamente descritas pela escola de Bühler. Nos textos lacanianos desse período, observa-se, em diversas passagens, uma tendência a tratar concomitantemente as situações de exibição, de sedução e de despotismo e as situações de transitivismo, como se fossem pertencentes à mesma classe de comportamentos, num movimento de "redução dos níveis do comportamento . . . mais atento à significação dos comportamentos do que à construção de seus mecanismos" (Jalley, 2011, p. 61), Assim, se justifica a atribuição dos créditos da teoria do transitivismo à psicologia do desenvolvimento de Bühler, mesmo que Lacan situe os comportamentos que o ilustram na faixa etária entre seis meses e dois anos, diferentemente das indicações da autora, que atribui esses comportamentos às crianças de menos de um ano (Jalley, 2011).

O núcleo fundamental do comportamento transitivista, na teoria lacaniana do período de 193649, é, pois, a confusão imaginária do eu com o outro, que dá origem às reações de rivalidade e agressividade. Consequentemente, a noção do um comportamento transitivista, como constitutiva da experiência original do sujeito, já tem de estar, de uma maneira ou de outra, presente substancialmente como categoria central nas formulações lacanianas do estádio do espelho desde o texto de 1938. Um único registro do termo "transitivismo" em "A família" (Lacan, 1938/1985) não significa necessariamente que essa noção não tenha já, naquele momento, uma importância teórica considerável, ainda que não apresente a mesma visibilidade que mostrará em textos posteriores dos anos 1940.

Não se pode dizer, no entanto, que o tema do ciúme fraterno e da significação subjetiva do ciúme em 
geral perca importância ao se subordinar ao conceito de transitivismo, como acontece nos trabalhos mais tardios desse período. Ao contrário, ao falar do transitivismo nos escritos dos anos 1940, inclusive no artigo sobre o estádio do espelho de 1949, Lacan remete às contribuições de Bühler para destacar, reiteradamente, como o drama do ciúme primordial é típico dos fenômenos do transitivismo. Ele leva em consideração que, fundamentalmente, o que Bühler traz em suas observações sobre o comportamento transitivista são os fenômenos em que duas crianças ficam juntas, se confundem e reagem com ciúme e agressividade uma à outra, configurando uma reação de rivalidade com o outro. Lacan evidencia, assim, a hipótese de que, desde 1938, o transitivismo já seria adotado como "o descritor principal da organização psíquica própria do estádio do espelho" (Jalley, 2011, p. 54). Na visão de Lacan, esse momento inaugura, pela identificação com a imago do semelhante e pelo drama do ciúme primordial, a dialética que desde então liga o eu a situações socialmente elaboradas (Lacan, 1949/1966). Ele teria, assim, encontrado, no conceito formulado por Bühler, uma categoria teórica que lhe permitiu dar sentido a uma série de observações psicológicas e clínicas que estão no centro de sua reflexão desde meados dos anos 1930, quando a noção de estádio do espelho aparece pela primeira vez.

Verificar e avaliar a dimensão do impacto das contribuições de Bühler para as formulações lacanianas permite, assim, constatar como as referências ao comportamento transitivista nas formulações iniciais do estádio do espelho retomam observações substanciais da autora acerca desse tema. Pode-se concluir que, desde o trabalho sobre os complexos familiares (Lacan, 1938/1985), o transitivismo já era uma categoria central na teoria do estádio do espelho, mesmo que discretamente. Essa centralidade se torna mais explícita na medida em que o drama do ciúme primordial passa a ser reiteradamente apresentado por Lacan, nos escritos dos anos 1940, como próprio dos fenômenos de transitivismo, com referências diretas às contribuições de Bühler.

Em suma, a diferença entre o trabalho sobre os complexos familiares de 1938 e os escritos lacanianos dos anos 1940 parece ser que, no primeiro, o comportamento transitivista aparece principalmente na descrição empírica do complexo de intrusão, com o outro imaginário cristalizado na figura do irmão rival. Já nos trabalhos mais tardios, o comportamento transitivista se emancipa desse complexo, apresentando-se nas relações imaginárias de confusão do eu com o outro em geral, dando sentido às reações de rivalidade e agressividade. Essa mudança assinalaria, assim, uma transição nas elaborações sobre o estádio do espelho nesse período, a passagem para outro nível de abstração conceitual. Desde o trabalho sobre "A agressividade em psicanálise" passa a ocorrer na obra lacaniana, ainda que sutilmente, um movimento em direção a uma perspectiva estrutural. Isso se manifesta, por exemplo, no emprego, por parte de Lacan, de expressões como "sincronias da captação especular" (Lacan, 1948/1966, p. 115) e outras semelhantes. Mesmo que a noção de sincronia não possua ainda o mesmo sentido que vai adquirir depois, seu emprego é indicativo de uma mudança de perspectiva. Esse movimento culmina no texto de 1949, com a adoção clara de um ponto de vista estrutural na reelaboração da teoria do estádio do espelho, que o afastará cada vez mais de uma perspectiva psicológica (Simanke, 2002). Pode-se considerar que a substituição da figura cristalizada do irmão como rival pela forma geral do outro, assim como a nova forma de se referir à contribuição de Bühler, esteja relacionada com esse movimento em direção à estrutura. Esse é um tema de pesquisa na história da constituição da teoria lacaniana do estádio do espelho que ainda precisaria ser mais detalhadamente explorado. Por ora, tratou-se apenas de identificar as implicações das conexões teóricas entre a teoria do imaginário desenvolvida por Lacan em sua obra inicial e a psicologia do desenvolvimento de Bühler e evidenciar a relevância dessas contribuições nesse momento da construção do corpus lacaniano - uma relevância que não parecia ainda ter sido suficientemente contemplada na literatura da área.

\section{Financiamento}

O presente artigo resultou da pesquisa de pósdoutorado em psicologia realizada no Programa de PósGraduação em Psicologia da Universidade Federal de Juiz de Fora, sob supervisão do professor doutor Richard Theisen Simanke, com financiamento do Conselho Nacional de Desenvolvimento Científico e Tecnológico (CNPQ), na modalidade de Pós-Doutorado Júnior (processo 168303/2017-15).

\section{The reception of Charlotte Bühler's concept of transitivism in Lacan's theory of the mirror stage}

Abstract: This article approaches Lacan's reception of Charlotte Bühler's concept of transitivism in the formulation of his theory of the mirror-stage between 1936 and 1949 in order to show how notions from the developmental psychology of the time were used in the construction of his thought. Bühler's specific contribution is argued to have been decisive both in the early formulation of the mirror-stage and in its subsequent development, culminating in the 1949 version, already closer to structuralist anti-psychologism. The rejection of a psychological interpretation of psychoanalytic concepts is shown to be unable of being regarded an original characteristic of Lacan's theory, appearing only at later stages of its development.

Keywords: Jacques Lacan, Charlotte Bühler, transitivism, imaginary order, mirror stage. 


\section{La réception du concept de transitivisme de Charlotte Bühler dans la théorie lacanienne du stade du miroir}

Résumé : L'article examine la réception par Lacan du concept de transitivisme de Charlotte Bühler dans l'élaboration de sa théorie du stade du miroir entre les années 1936-1949 afin de montrer comment les notions de la psychologie du développement de l'époque ont été incorporées dans la construction de sa pensée. On soutient que la contribution spécifique de Bühler a été décisive à la fois dans la formulation initiale du stade du miroir et dans son développement ultérieur, aboutissant à la version de 1949, qui est déjà plus proche de l'antipsychologisme structuraliste. En conclusion, on discute comment le rejet d'une interprétation psychologique des concepts psychanalytiques ne peut pas être considéré comme une caractéristique originaire de la théorie lacanienne, ne provenant que des étapes ultérieures de son développement.

Mots-clés : Jacques Lacan, Charlotte Bühler, transitivisme, imaginaire, stage du miroir.

\section{La recepción del concepto de transitivismo de Charlotte Bühler en el concepto lacaniano del estadio del espejo}

Resumen: El artículo examina la recepción por Lacan del concepto de transitivismo de Charlotte Bühler en la elaboración de su concepto del estadio del espejo entre los años 1936-1949, a fin de mostrar cómo nociones provenientes de la psicología del desarrollo de la época fueron incorporadas en la construcción de su pensamiento. Se argumenta que la contribución específica de Bühler fue decisiva tanto en la formulación inicial del estadio del espejo como en su posterior desarrollo que culminó en la versión de 1949, ya más cercana al antipsicologismo estructuralista. En conclusión, se discute cómo el rechazo de una interpretación psicológica de los conceptos psicoanalíticos no puede ser considerado una característica originaria de la teoría lacaniana, la cual surgió solamente a partir de etapas posteriores de su desarrollo.

Palabras clave: Jacques Lacan, Charlotte Bühler, transitivismo, imaginario, estadio del espejo.

\section{Referências}

Bolk, L. (1961). Le problème de la genèse humaine. Revue Française de Psychanalyse, 25(1), 243-280. (Trabalho original publicado em 1926)

Bühler, C. (1934). El desarrollo psicológico del niño. Buenos Aires: Losada. (Trabalho original publicado em 1927)

Bühler, C. (1959). Infancia y juventude. Buenos Aires: Espasa-Calpe. (Trabalho original publicado em 1931)

Cavalcante, R. M. (2014). O estádio do espelho na obra de Jacques Lacan entre os anos de 1936 e 1949 (Dissertação de mestrado). Instituto de Psicologia, Universidade Federal de Alagoas, Maceió, AL.

Corniglio, F. (2013). El niño lacaniano, entre Bühler y Kojève (1938-1948). In V Congresso Internacional de Investigación y Práctica Profesional em Psicología. $X X$ Jornadas de Investigación. Noveno Encuentro de Investigadores em Psicología del Mercosur (pp. 36-40). Simpósio apresentado na Faculdade de Psicologia da Universidade de Buenos Aires, Buenos Aires.

Corniglio, F. (2014). Algunas referencias de Lacan a la psicologia del desarrollo de Charlotte Bühler (1936-1948). Revista Psicologia em Pesquisa, 8(1), 41-52.

Dunker, C. I. L. (2011). Transitivismo e letramento: constituição do sujeito e entrada no discurso alfabético. Recuperado de http://bit.ly/2IzQtfX

Jalley, É. (2011). Freud, Wallon, Lacan: a criança no espelho. Rio de Janeiro, RJ: Cia de Freud.
Jorge, M. A. C., \& Ferreira, N. P. (2005). Lacan: o grande freudiano. Rio de Janeiro, RJ: Jorge Zahar.

Lacan, J. (1953). Some reflections on the ego. International Journal of Psychoanalysis, 34(1), 11-7.

Lacan, J. (1966). Au-delà du 'Principe de réalité'. In Écrits (pp. 73-92). Paris: Éditions du Seuil. (Trabalho original publicado em 1936)

Lacan, J. (1966). L'agressivité em psychanalyse. In Écrits (pp. 101-124). Paris: Éditions du Seuil. (Trabalho original publicado em 1948)

Lacan, J. (1966). Le stade du miroir comme formateur de la fonction du Je. In Écrits (pp. 93-100). Paris: Éditions du Seuil. (Trabalho original publicado em 1949)

Lacan, J. (1966). Propos sur la causalité psychique. In Écrits (pp. 151-193). Paris: Éditions du Seuil. (Trabalho original publicado em 1950)

Lacan, J. (1975). De la psychose paranoïaque dans ses rapports avec la personnalité. Paris: Seuil. (Trabalho original publicado em 1932)

Lacan, J. (1985). Os complexos familiares. Rio de Janeiro, RJ: Jorge Zahar. (Trabalho original publicado em 1938)

Lacan, J. (2005). Discurso de Roma. In Outros escritos (V. Ribeiro, trad., pp. 19-172). Rio de Janeiro, RJ: Jorge Zahar. (Trabalho original publicado em 1953)

Lyden, C. (2008). Through the mirror and beyond: understanding Lacan's mirror stage. Psychoterapy in Australia, 14(2), 50-53. 
Oliveira, R. H. (2017). A gênese da teoria lacaniana do estágio do espelho: os materiais para construção (Dissertação de mestrado). Instituto de Ciências Humanas, Universidade Federal de Juiz de Fora, Juiz de Fora, MG.

Sales, L. S. (2005). Posição do estágio do espelho na teoria lacaniana do imaginário. Revista do Departamento de Psicologia-UFF, 17(1), 113-127.

Simanke, R. T. (2002). Metapsicologia lacaniana: os anos de formação. Curitiba, PR: Discurso Editorial.
Vestegen, I. (2015). Lacan and Gestalt Theory, with some suggestions for cultural studies. Gestalt Theory, 37(3), 273-286.

Wallon, H. (1989). As origens do pensamento na criança. São Paulo, SP: Manole.

Recebido: $25 / 11 / 2017$

Revisado: $14 / 02 / 2019$

Aprovado: 25/02/2020 